\title{
Letters
}

\section{Diagnosis of autism}

\section{Adequate funding is needed for assessment services}

EDitor-In their clinical review of the diagnosis of autism Baird et al highlight the need for a multiagency process of assessment and supportive intervention to be made available to all children presenting with concerning symptoms, in accordance with the recommendations of recent national reviews. ${ }^{1-3}$ One important additional reason for such provision, which their review does not emphasise, is that well coordinated, multiagency assessment teams for autism spectrum disorders have a better chance of accurately not giving a diagnosis of it.

Our multiagency assessment service for autism spectrum disorders has seen 57 patients in the past two years. We request baseline speech and language therapy and (where applicable) educational psychology assessments on the likelihood of autism spectrum disorder in all cases before patients are seen by our team, so as to ensure best use of clinical resources. Despite this approach only 26 patients $(46 \%)$ deemed to be likely cases of autism spectrum disorder received a positive diagnosis. This is not due to overzealous interpretation of ICD-10 diagnostic criteria (which are increasingly recognised as being in urgent need of review), as we tend, if anything, to err in favour of diagnosis, even if ICD-10 (or DSM-IV) criteria, are not strictly fulfilled.

Relevant agencies must receive adequate funding for implementing the national autism plan for children. ${ }^{3}$ This is to benefit not only the children and their families who are struggling with the often devastating impact of this disorder but also the depressingly high number of children whom, we suspect, will be wrongly, or inaccurately, given diagnoses, if assessment services for autism spectrum disorders do not improve.

Iain McClure consultant child and adolescent psychiatrist

imcclure@vol.scot.nhs.uk

imcclure@vol.scot.nhs.uk Roslyn McCaughey senior speech and language therapist

Acorn Centre, Vale of Leven Hospital, Alexandria, G83 0UA
1 Baird G, Cass H, Slonims V. Diagnosis of autism. BMJ 2003;327:488. (30 August.)

Public Health Institute of Scotland Autistic spectrum disorders needs assessment report. Glasgow: PHIS, 2001. 3 Le Couteur A, Baird G, National Initiative for Autism Screening and Assesment Screening and Assessment (NIASA). National autism plan

Current epidemic has social context

EDITOR-In their article on the diagnosis of autism Baird et al completely ignore context. ${ }^{1}$ They focus on an explanation within the child for the rapid rise in rates of diagnosis, implying that the only cultural factor affecting this has been low rates of recognition in the past.

The immaturity of children may be a fact of biology, but the meaning ascribed to this immaturity is a fact of culture. Without any tangible evidence of organic pathology and any biological tests to substantiate our hypothesis of a neurological dysfunction, the boundaries of the disorder can expand endlessly and are dependent on the subjective opinion of the person making the diagnosis. ${ }^{2}$

Our notions of child development are culture bound and too often create a blueprint of age dependent expectations that ordinary parents fear our children cannot meet, rather than a set of required behaviours that our children must master if they are to be considered fully human. And why the over-representation of boys?

In my clinical practice I often come across children and adolescents who are labelled autistic. When I focus on their abilities I often find much about them that does not fit the autistic discourse. Once I reopen the question of diagnosis many adolescents ask me to officially "undiagnose" them, which their parents are usually very pleased about.

We can and should do better than this relentless medicalisation of children and must become more competent at integrating medical theory with other perspectives, otherwise we will soon have a grown up generation of children (mainly boys) who have become unnecessarily convinced that they are somehow deficient and incapable.

Sami Timimi consultant child and adolescent psychiatrist

Ash Villa, Sleaford, Lincolnshire NG34 8QA stimimi@talk21.com

Competing interests: None declared.
1 Baird G, Cass H, Slonims V. Diagnosis of autism. BMJ 2003;327:488. (30 August.)

2 Timimi S. Pathological child psychiatry and the medicalization of childhood. Hove: Brunner-Routledge, 2002.

\section{Use of autistic spectrum shows} undisciplined thinking

EDITOR-The use by Baird et al in their clinical review of the diagnosis "autism" and "autistic spectrum disorders" confuses me. The authors list five outcomes in box 8 that indicate the success of therapeutic and teaching interventions and may help us to comprehend what is the cardinal feature of autism: normal use of verbal language, some use of verbal language for a range of purposes, some functional use of language, ability to use an alternative system of communication, the child's idiosyncratic communication is better understood.

In each of these five successful outcomes for autism is one constant thread-the abnormal use of language for communication. I suggest that autism is none other than this-as opposed to the delayed development of speech. If that is so, then we do not need a spectrum any more than we need an asthmatic spectrum or a diabetic spectrum.

The diagnosing clinician must decide either that the child has autism or he or she does not have autism. If there is uncertainty, then this can be expressed reasonably. Responsible clinicians can justifiably give some idea of the severity of the autism by saying that it is severe or it is moderate or it is mild.

I believe that the use of autistic spectrum (as opposed to a straightforward diagnosis of autism) is undisciplined thinking. Either children have abnormal use of language for communication or they do not. Don't leave them on the autistic spectrum when you cannot come to a clear and definite diagnosis of autism.

P V Finn Cosgrove consultant all-age psychiatrist Bristol Priority Clinic, Bath BA2 5YD bristolpriorityclinic@btopenworld.com

Competing interests: PVFC is a specialist in the diagnosis and treatment of attention deficit hyperactivity disorder in children, adolescents, and adults

1 Baird G, Cass H, Slonims V. Diagnosis of autism. BMJ 2003;327:488. (30 August.)

\section{Autism seems to be increasing worldwide, if not in London}

EDITOR-It would be wonderful if autism had reached a plateau in northeast London, as reported by Mayor. ${ }^{1}$ Unfortunately, this has not happened anywhere else. 
In Cambridgeshire one in 175 children in school had a diagnosis of autism in 2001 (F Scott, personal communication). According to a recently reported study by the Highland Council Education Department, as many as one primary schoolchild in 49 has been diagnosed with, or is awaiting diagnosis of, autistic spectrum disorder in the Inverness area. ${ }^{2}$

In the United States, where criteria from the Diagnostic and Statistical Manual, fourth revision have been exclusively used since 1994, 28813 children aged 6-21 with autism attended school in 1995-6 compared with 118603 in 2002-3, an annual increase of $18-26 \%$, according to official reports to Congress. ${ }^{3}$ The California Department of Developmental Services reported that 3577 children with new cases of autism accessed services in 2002 (10 cases a day) compared with 633 in 1994. With an increase of $97 \%$ in the past four years, autism has become the top disability requiring initiation of services in the state. The last yearly increase of $31 \%$ is the largest in 33 years. ${ }^{4}$

In Canada's Province of Quebec the number of children with pervasive developmental disorders in schools increased by $63 \%$ in two years, from 1388 in September 2001 to 2267 in September 2003 according to the Ministry of Education of Quebec $(\mathrm{C}$ La Haie, fourth international medical conference on autism, Montreal, November 2003).

Lastly, in Saudi Arabia (population under 23 million) there were 42500 confirmed cases of autism in 2002, and many more cases remain undiagnosed.

Taylor's raw data have remained inaccessible since 1999, when he first denied any connection between autism and measles, mumps, and rubella vaccination, in a study that neither had a population based cohort design nor sufficient statistical power to detect an association." ${ }^{\mathrm{w} 1 \mathrm{w2} \text { w3 }}$

F Edward Yazbak paediatrician

TL Autism Research, 70 Viewcrest Drive, Falmouth, MA 02540, USA

TLAutStudy@aol.com

Competing interests: Grandfather of a boy with regressive autism, typical "autistic" enterocolitis, and evidence of measles genomic RNA in the gut wall.

Mayor S. Apparent increase in autism in children has Mayor S. Apparent increase in autism in children
stopped, study shows. BMJ 2003;327:248. (2 August.)

2 Shock as incidence of autism soars in city. Inverness Courier 2003 Dec 5. Available at: http://wwwinvernesscourier.co.uk/news.asp?storyvar=8469 (accessed 15 Jan 2004).

3 Twenty-sixth Annual Report to Congress on the Implementation of the Individuals with Disabilities Education Act. To Assure the Free Appropriate Public Education of All tion Act. To Assure the Free Appropriate Public Education of All
Children with Disabilities (Section 618). Washington, DC: US Children with Disabilities (Section 618). Washington, DC: US
Department of Education, 2003.

California Department of Developmental Services. Autism spectrum disorders. Changes in the California caseload An update: 1999 through 2002. Sacramento, CA: Department of Developmental Services, 2003. (www.dds.ca.gov/ autism/pdf/AutismReport2003.pdf )

5 Ramadan G, Alkhereiji M. Animal-assisted therapy works wonders. Arab News 2002 Oct 9. Available at: www.najaco.com/travel/news/saudi_arabia/2002/ october/9.htm (accessed $16 \mathrm{Jan} 200 \overline{3})$.

References w1-3 are published on bmj.com

\section{Guidelines on neuraminidase inhibitors in children are not supported by evidence}

EDITOR-Guidelines from the National Institute for Clinical Excellence (NICE) on the use of neuraminidase inhibitors recommend oseltamivir for the treatment of at risk children with influenza-like illness of fewer than 48 hours' duration-for example, those with underlying chronic respiratory disease. The drug is not recommended for otherwise healthy children.

In our systematic review on the use of neuraminidase inhibitors in children, however, we found no published studies on the effectiveness of oseltamivir in reducing the duration of illness in at risk, rather than healthy, children. ${ }^{2}$ Despite this, unpublished data from at risk children seem to exist and were made available by the manufacturers of oseltamivir during their application for European Marketing Authorisation for the drug. In the ensuing European Public Assessment Report, reference is made to results from 178 children with chronic asthma and confirmed influenza infection enrolled in study WV15759/WV15871. The stated difference in time to freedom from illness between children receiving placebo and children receiving oseltamivir is statistically non-significant, at only 10.3 hours (a reduction of $8 \% ; \mathrm{P}=0.54$ ).

The failure to publish study WV15759/ WV15871 seems to be an example of publication bias. Furthermore, these unpublished data, although distributed to the European Agency for the Evaluation of Medicinal Products, seem not to have been made available to NICE. Certainly, the systematic review commissioned by NICE to inform their guidance, abbreviated in the $B M J$, excluded the study because there were no data. $^{45}$

In the absence of these data, and by assuming the benefits of neuraminidase inhibitors to be greatest in children at highest risk of complications of influenza, NICE has acted to focus the use of oseltamivir in children on those at risk-the very population for whom the evidence of benefit is weakest.

Mkael Symmonds preregistration house officer Department of Surgery, Ayr Hospital, Ayr KA6 Depa mkael@doctors.org.uk

Nicholas J Matheson preregistration house officer Department of Medicine, John Radcliffe Hospital, Oxford OX3 9DU

Anthony Harnden university lecturer

Department of Primary Health Care, Institute of Health Sciences, Oxford OX3 7LF

Competing interests: None declared.

1 National Institute for Clinical Excellence. Technology Appraisal guidance No 58. London: NICE, 2003. http:/
anstionate for Clical Excellence. Techology appraisal guidance No 58 . London: NICE, 2003.

www.nice.org.uk/pdf/58_Flu_fullguidance.pdf
2 Matheson NJ, Symmonds-Abrahams M, Sheikh A, Matheson NJ, Symmonds-Abrahams M, Sheikh A,
Shepperd S, Harnden A. Neuraminidase inhibitors for Shepperd S, Harnden A. Neuraminidase inhibitors for preventing and treating influenza in children (Cochrane
Review). In: The Cochrane Library, Issue 3, 2003. Oxford: Review). In: The Update Softwar

Arency for the Evaluation of Medicina Products. Tamiflu. European Public Assessment Report 2002. http://www.eudra.org/humandocs/humans/epar/ tamiflu/tamiflu.htm
4 Turner D, Wailoo A, Nicholson K, Cooper N, Sutton A, Turner D, Wailoo A, Nicholson K, Cooper N, Sutton A, elling for the prevention and elling for the . Health Technology Assessment

5 Cooper NJ, Sutton AJ Abrams KR, Wailoo A, Turner DA , in trelson KG. Effectiveness of neuraminidase inhibitor in treatment and prevention of influenza A and B: systemtrials. BMJ 2003:326:1235-40.

\section{Children need international formulary to guarantee rational use of drugs}

EDITOR-The unsatisfactory standing of children with regard to evidence based drug treatment is well documented. ${ }^{1}$ Information on drug use in children is lacking, and differences in therapeutic approaches are wide, which implies the need for harmonisation.

An example of a concrete effort to fulfil this need is Medicines for Children, a paediatric formulary aimed at helping those who prescribe for children or who dispense for or give drugs to them. ${ }^{2}$ A formulary's main objective, in fact, is not simply to list drugs and their therapeutic profile but to function as a tool for rationally using drugs. A formulary must be a source of up to date, evidence based information for the most common clinical problems in and out of hospital.

Researchers in Italy have joined in the United Kingdom's efforts of compiling a national formulary by creating an Italian version of the formulary, adapted to the Italian context, entitled Guida all'uso dei farmaci per $i$ bambini [guide to the use of drugs for children], which all Italian doctors, nurses, and pharmacists (about 600000 ) receive free of charge. ${ }^{3}$ This initiative was set up under the auspices (technical and economic) of Italy's Ministry of Health and is unique nationally and internationally.

Past and current efforts, including legislative measures in different countries, guide the way to a greater challenge. The joint participation of different countries in setting up a European formulary led by an international committee would be a valuable achievement and should be supported.

The project would be a challenge for the European Community and would result in consensus on drug treatments for children (a qualitative and quantitative synthesis of the evidence ${ }^{4}$ ), guaranteeing all children the same approved, acknowledged treatments to which they are entitled.

Maurizio Bonati head

Chiara Pandolfini senior researcher pandolfini@marionegri.it

Laboratory for Mother and Child Health, "Mario Negri" Pharmacological Research Institute, Via Eritrea 62, 20157 Milan, Italy

CP is supported in part by a Monzino fellowship. Competing interests: None declared.

1. Pandolfini C, Bonati, M. Off-label drug use in children in Europe: a major health issue. Pharm Dev Regul 2003;1:133-

2 Royal College of Paediatrics and Child Health. Medicines for children. London: British Medical Association, 1999. 3 Ministero della Salute. Guida all'uso dei farmaci per ambini Rome: Istituto Poligrafico e Zecca dello Stato, 0003.

Chalmers I, Hedges LV, Cooper H. A brief history of research synthesis. Eval Health Prof 2002;25:12-37. 


\section{Prescription of heroin to treatment resistant heroin addicts}

\section{Double blinding is not possible}

EDITOR-As mentioned in the discussion of the paper by van den Brink et al, ${ }^{1}$ experiments with heroin maintenance cannot be double blind. This problem is much more serious than the authors acknowledge, particularly because considerable sanctions were connected to the participants' responses.

The participants in the control groups knew that the promise of heroin maintenance later on could be withdrawn if they improved during the control period without heroin on prescription. Moreover, the participants in the experimental groups knew that they could be expelled from the experiment if they deteriorated while receiving heroin. Finally, the participants who improved while receiving heroin were aware that they would have a fair chance of continued heroin on prescription provided that they deteriorated in an interim period without heroin provision. Even if improvement could have been measured fully unobtrusively rather than with self reports, this would have created serious problems.

However, it is not certain that the results are positively biased because of this. It means that heroin experiments are tests in the sense of examinations rather than scientific experiments. If much is at stake in examinations people might fail not because they lack skills but because the tests are too nerve racking. This may have suppressed the results.

Europe is currently flooded by a tidal wave of expensive and demanding heroin maintenance experiments. Even if these experiments could be conducted as double blind trials there are other reasons why experimental studies are inappropriate in such cases. ${ }^{23}$

Trudy Dehue professor of theory and history of psychology

University of Groningen, 9712 TS Groningen, Netherlands

t.dehue@ppsw.rug.nl

Competing interests: None declared.

1 Van den Brink W, Hendricks VM, Blanken P, Koeter MWJ, van Zwieten BJ, van Ree JM. Medical prescription of heroin to treatment resistant heroin addicts: two randomised controlled trials. BMJ 2003;327:310-2. (9 August.)

2 Dehue TA Dutch treat. Randomized controlled experimentation and the case of heroin maintenance in the Netherlands. Hist Human Sci 2002;15:75-98.

3 Dehue T. Antwoord op de brief van Minister Borst. Maand blad voor Geestelijke Volksgezondheid 2002;9;806-11.

Replacement therapies need to be tested on a level playing field

EDITOR-The study of medical prescription of heroin by van den Brink et al should be interpreted with caution. ${ }^{1}$

Firstly, the selection of opiate dependent patients with at least four weeks of continuous treatment in the past five years does not define resistance to treatment with methadone treatment, but rather, early treatment intervention. This may explain the substantial treatment response to longer term methadone in the control group, where the only intervention is randomisation into a controlled trial.

Secondly, in such a study taking methadone and heroin dosage levels into account is crucial when evaluating clinical outcome; adequate doses of opiate replacement are critical to treatment success. ${ }^{2}$ Actual doses are reported only in the electronic version of the paper and show that doses of combined heroin and methadone in the heroin treatment groups are about $20 \%$ higher in terms of methadone equivalents compared with the control methadone only treatment group. Furthermore, this latter group received a mean methadone dose of about $75 \mathrm{mg} /$ day, which may be suboptimal. The discrepancy in methadone dosage equivalents between the two groups may account for the apparently favourable effects of additional heroin.

Lastly, the deterioration after discontinuing heroin at the end of the study may simply reflect a transition from adequate to inadequate amounts of prescribed opiate replacement therapy.

Heroin treatment needs robust evaluation as it is intensive and expensive compared with other opiate replacement drugs, including methadone and buprenorphine. ${ }^{3}$ Clinical studies comparing heroin with other opiate replacement therapies need to be conducted on a level playing field.

Laurence J Reed specialist registrar

spdpljr@iop.kcl.ac.uk

Cornelis de Wet specialist registrar

Jennifer Bearn consultant

Bethlem Roval Hospital, South London and

Maudsley NHS Trust, Beckenham, Kent BR3 3BX

Competing interests: None declared.

1 Van den Brink W, Hendricks VM, Blanken P, Koeter MWJ, Van Zwieten BJ, Van Ree JM. Medical prescription of heroin to treatment resistant heroin addicts. two randomise controlled trials. BMJ 2003;327:310-2. (9 August)

2 Dole VP, Nyswander M. Successful treatment of 750 criminal addicts. JAMA 1967;206:2708-11.

3 Ferri M, Davoli M, Perucci CA. Heroin maintenance for chronic heroin dependents Cochrane Database Syst Rev
2003;4:CD003410.

\section{Treatment needs to be multifaceted}

EDITOR-That $45-88 \%$ of the participants in the study of van den Brink et al did not respond to the co-prescription of heroin is disappointing. ${ }^{1}$

As a general practitioner I see daily the interaction between patients' wellbeing and their social circumstances. Poor housing, unemployment, and chronic relationship difficulties are well recognised contributors to the illness behaviour. In the treatment of heroin addicts we need to take a multifaceted approach to their treatment. My anecdotal experience has been that those addicts who are either in employment or who are able to find employment while in treatment fare better than those who remain unemployed.

I long to see the day when we are able to provide a community based drug treatment programme that offers the provision of housing, sheltered employment, drug treatment, and psychological support together. If rehabilitation is our serious aim we need to provide a much more coordinated treatment programme or we will be forever disappointed with the long term results.

Iain B Craighead general practitioner principal Faringdon Health Centre, Faringdon, Oxfordshire SN7 7YU

Craighead@doctors.org.uk

Competing interests: None declared.

1 Van den Brink W, Hendricks VM, Blanken P, Koeter MWJ, van Zwieten BJ, van Ree JM. Medical prescription of heroin to treatment resistant heroin addicts: two randomised controlled trials. BMJ 2003;327:310-2. (9 August.)

\section{Dutch heroin trials show retention is}

better with methadone alone

EDITOR-The conclusion by van den Brink et al that medical co-prescription of heroin to treatment resistant heroin addicts was more effective than methadone alone is not supported by all of their data. ${ }^{1}$ Rather, the better quality retention data significantly favour the methadone only group.

The trialists' claim that heroin co-prescription is superior to routine methadone maintenance is based on a higher proportion of subjects showing overall improvement on a dichotomous, multidomain outcome index. ${ }^{1}$ However, the measures making up the index were based on self reports and likely to be biased in favour of the heroin groups because the study was not blinded and subjects given heroin were transferred to special, new clinics. The performance ratings are more a measure of the heroin subjects' enthusiasm for the new treatment centres and the legal use of heroin.

The trialists present separate sets of retention data for subjects who injected and inhaled heroin. When these are combined in fixed effects meta-analyses they show that subjects receiving methadone only were $23 \%$ more likely to be in treatment at the end of 12 months (relative risk, 95\% confidence interval $11 \%$ to $37 \%, \mathrm{P}=0.0001$ ). It is necessary to give only seven methadone patients access to heroin to cause one premature loss in the first 12 months of methadone maintenance treatment (number needed to treat to harm, 4.2 to 12.0).

The results of the Dutch trials show that patients on methadone maintenance attending a clinic an average two times a day to use heroin are significantly more likely to be lost to treatment than other patients receiving methadone. This finding highlights the need to evaluate programmes that provide maintenance patients with heroin for use at a time and in a place of their choosing.

John Caplehorn senior lecturer

Clinical Epidemiology, School of Public Health,

A27 University of Sydney, Sydney, NSW 2006,

Australia

johnc@health.usyd.edu.au

Competing interests: None declared. 
1 Van den Brink W, Henricks VM, Blanken P, Koeter MWJ, van Zwieten BJ, van Ree JM. Medical prescription of heroin Van Zwieten BJ, to treatment resistant heroin addicts: two rand
trolled trials. BMJ 2003;327:310-2. (9 August.)

\section{Heroin handouts are flawed policy}

EDITOR-We question the conclusions of van den Brink et al, who say that the use of heroin is comparable or perhaps better than methadone for resistant addicts. ${ }^{1}$ Their measures of efficacy should raise serious questions as to the validity of the study. Deterioration of up to $40 \%$ in performance measure, or increases of cocaine or amphetamine of up to $20 \%$, were deemed successes as long as at least one of three measures improved by at least $40 \%$.

To consider deterioration of performance measures of up to $40 \%$ as acceptable smacks of manipulating measures of success to fit the data. A $40 \%$ deterioration is staggering and should be considered a clear failure.

Finally, even the authors concede that $45-88 \%$ of the participants did not respond to the heroin handout, yet they consider it a success. We are also not presented with the hard data on HIV or hepatitis conversion rates during the heroin handout. We are not given data on criminality or breadth of illegal drugs used.

Fundamentally, the medical world needs to understand that heroin handouts are simply keeping addicts addicted. As seen in Switzerland, heroin handouts simply further the addiction and enslavement of suffering addicts. $^{2}$ Creative approaches such as those used in Sweden should be examined and implemented to press users more rigorously towards abstinence."

Eric A Voth chairman

Internal Medicine and Addiction Medicine, Institute on Global Drug Policy, St Petersburg, FL 33701, USA

EVoth@stormontvail.org

Ernst Aeschbach doctor

Private Practice of Psychiatry, Bettackerstrasse 7 ,

CH-8152 Glattbrugg, Switzerland

Competing interests: None declared.

1 Van den Brink W, Henricks VM, Blanken P, Koeter MWJ, van Zwieten BJ, van Ree JM. Medical prescription of heroin to treatment resistant heroin addicts: two randomised controlled trials. BMJ 2003;327:310-2. (9 August.)

2 Satel SL, Aeschbach E. The Swiss heroin trials: scientifically sound? J Subst Abuse Treat 1999;17:331-5.

3 Sullivan L. Drug policy: a tale of two countries. News Weekly 1999 Aug 28:7.

\section{Authors' reply}

EDITOR-Dehue thinks that our study was a nerve racking test for the patients because considerable sanctions were connected with participants' treatment responses. This is based on the false assumptions that patients would be expelled from the experiment if they deteriorated while receiving heroin and that patients in the control condition would lose their opportunity to enter heroin assisted treatment if they improved during the treatment with methadone alone. Measures on illicit drug use and criminal activities showed excellent agreement with urine analysis and police register data, indicating that patients in the trial were accurate and reliable in their reporting.

Reed et al assume that patients were required to be in continuous methadone maintenance treatment for only four weeks in the previous five years. Study participants were in methadone treatment for around 12 years on average and were using methadone 28 days in the month before the start of the trial. At the end of the trial the methadone dosage in the experimental groups was on average about $10 \mathrm{mg}$ lower than in the control groups, but this difference was neither significant nor clinically relevant. Therefore a difference in methadone dosage between the treatment conditions is unlikely to have accounted for the observed efficacy of medically prescribed heroin.

Craighead finds it disappointing that $45-88 \%$ (actual data 45-78) of the participants did not respond to co-prescribed heroin. We believe that $22-55 \%$ response in a chronic, treatment resistant population of heroin addicts with very few assets, serious health problems, and massive social impairments is a substantial effect.

We disagree with Caplehorn's conclusion that the study data favour continuation of methadone treatment in this population. Although treatment retention is often a prerequisite for treatment effectiveness, retention can never replace effectiveness data (response) in establishing efficacy. Additional analyses show that the observed efficacy of heroin prescription is not due to some Hawthorn or Honeymoon effect (www.ccbh.nl).

Voth and Aeschbach question the validity and clinical relevance of the primary outcome variable of the study. In the trial, similar results in favour of the heroin assisted treatment were obtained with various other response definitions, including definitions that did not allow any deterioration or increase in cocaine use. Heroin prescription resulted in modest reductions in cocaine use and large reductions in criminality.

With regard to their final statement, we refer to Rehm et al, who showed that after five years only $34 \%$ of the patients were still in heroin assisted treatment and that most of the patients who left the heroin programme started another treatment, generally methadone maintenance or abstinence treatment. ${ }^{1}$ The view that heroin assisted treatment furthers the addiction and enslavement of suffering addicts is therefore not supported by the data. In contrast, the findings indicate that heroin assisted treatment can be a useful addition to the treatment armature available for these suffering, chronically impaired patients.

Wim van den Brink professor

Peter Blanken researcher

Central Committee on the Treatment of Heroin addicts $(\mathrm{CCBH})$, Stratenum, $5^{\mathrm{e}}$ verdieping, Universiteitsweg 100, 3584 CG Utrecht, Netherlands w.vandenbrink@amc.uva.nl

Vincent M Hendriks senior researcher

Parnassia Addiction Research Centre, PO Box 53002, 2505 AA Den Haag, Netherlands

Additional authors are Maarten W J Koeter, Amsterdam Institute for Addiction Research, Tafelbergweg 25, 1105 BC Amsterdam, Netherlands; Barbara J van Zwieten, Netherlands Medicines Evaluation Board, Kalvermarkt 53,
Den Haag, Netherlands; Jan M van Ree, Rudolf Magnus Institute of Neuroscience, Utrecht University, Stratenum, $5^{\mathrm{e}}$ verdieping, Universiteitsweg 100, 3584 CG Utrecht, Netherlands.

Competing interests: None declared.

1 Rehm J, Gschwend P, Steffen T, Gutzwiller F, DoblerMikola A, Uchtenhagen A. Feasibility, safety, and efficacy of injectable heroin prescription for refractory opioid addicts: a follow-up study. Lancet 2001;358: 1417-20.

\section{Britain's failure to tackle research misconduct}

\section{Britain is ahead of most countries}

EDITOR-Lock warns the medical community about its lack of action in handling research misconduct. ${ }^{1}$ We disagree that Britain lags behind the rest of the world and think that Lock should be proud of the achievements of the Anglo-Saxon countries. Fewer than 10, mostly small, countries have a national body for investigating misconduct and fraud in science, and few countries have open discussions under the auspices of professional organisations such as the Committee on Publication Ethics (COPE). Eastern and southern Europe, Latin America, and Asia have no mechanisms for handling fraud properly.

If 23 years have not been sufficient for Britain to move on, will countries such as France have to wait until 2020 or 2050 to see improvement? A series of high profile cases that exposed fabrications of data in the late 1970 s and early '80s in the United States resulted in the Health Research Institution Act 1985, which required institutions to establish procedures for addressing scientific misconduct. ${ }^{2}$ However, the situation in the United States is still far from satisfactory. Establishing standards, recommendations, and processes for investigating research misconduct takes time as so many interests are challenged. Professional organisations must be well organised and governments supportive.

Lock says that a scandal and a charismatic leader are needed before progress can be made. But must we wait to see a major scandal in the public domain in most countries? Will a scandal be sufficient in countries where misconduct is discussed and handled behind closed doors? And one charismatic opinion leader per country is not enough.

Herv Maisonneuve associate professsor

hervemaison@wanadoo.fr

Alain Bérard research assistant

Dominique Bertrand head

Public Health Department, Lariboisière Fernand

Widal Hospital, 200 rue du Faubourg St Denis, 75010 Paris, France

Competing interests: None declared.

I Lock S. Britain prefers talk to action. BMJ 2003;327:940-1. (25 October.)

2 Mello MM, Brennan TA. Due process in investigation of research misconduct. N Engl J Med 2003;349:1280-6.

UK bodies are now working together to set up panel on misconduct

EDITOR-We sympathise with Lock's frustration about the delay in establishing a British panel for preventing and managing 
biomedical research misconduct. ${ }^{1}$ Having produced this college's consensus conference statement, ${ }^{2}$ we worked with sister colleges to develop a blueprint for such a panel. ${ }^{3}$ The subsequent development of the panel was charged by UK colleges and other relevant bodies to the Academy of Medical Sciences. This item has been monitored closely by our audit and research committee, and, like Lock, we are disappointed that the academy has not made more progress.

After the meeting of the Committee on Publication Ethics (COPE) in October, where Lock spoke, it was proposed that the colleges should work with the General Medical Council, Universities UK, NHS Research and Development, and the Academy of Medical Sciences to ensure the progression of the panel. The Federation of Royal Colleges of Physicians of the UK has since confirmed its support for the joint working group. This college continues to promote its misconduct statement and remains fully committed to working actively with all other bodies to establish the British panel.

\section{Gordon D O Lowe assessor}

gdl1j@clinmed.gla.ac.uk

Gordon D Murray member, Consensus Panel on

Misconduct in Biomedical Research

Niall D Finlayson president

Royal College of Physicians of Edinburgh,

Edinburgh EH2 1JG

Competing interests: None declared.

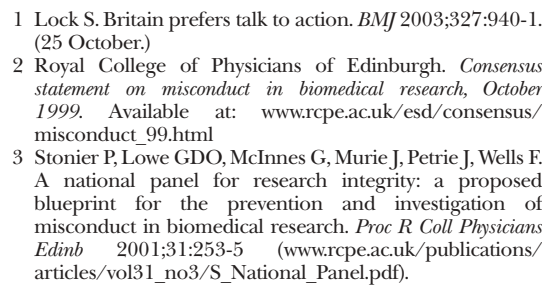

1 Lock S. Britain prefers talk to action. BMJ 2003;327:940-1. (25 October.)

2 Royal College of Physicians of Edinburgh. Consensus soyal College of Physicians of Edinburgh. Consensus 1999. 199. Available al: mwn.repeacnk/esd/consensus/

3 Stonier P, Lowe GDO, McInnes G, Murie J, Petrie J, Wells F. A national panel for research integrity: a proposed A national panel for research integrity: a proposed blueprint for the prevention and investigation of misconduct in bionedical research. Proc $R$ Coll Physicians articles/vol31_no3/S_National_Panel.pdf).

\section{Editors and their priorities about libel and fraud}

\section{We need whistleblowers}

EDITOR-I have followed the rapid responses to the report of the HealthWatch Award address by Peter Wilmshurst. ${ }^{2}$ Having worked with Wilmshurst (he was my registrar 30 years ago) I can confirm Beardsell's opinion that he is not just a troublemaker but an unusually honest doctor who has his patients' best interests at heart. ${ }^{2}$

Syed says that local research committees should monitor experimental data, and Goodman and Hutchon say that the data should be available on the internet. ${ }^{2}$ This may detect fraud in formal clinical trials, but it would not work well for other types of dishonesty. For example, Banerjee reported a falsely increased number of rats on which he experimented, as well as a falsely large number of senior colleagues associated with the research. ${ }^{3}$ Pearce falsely reported a successful outcome with an extrauterine pregnancy, but the case was fictitious. Neither experiment would usually be moni- tored by a local ethics committee, and data on the internet would not necessarily expose the fraud. Different types of dishonesty need different methods of control.

Wilmshurst suggested checks of publication honesty analogous to dope testing in athletes. This is a false analogy, because dope testing is comparatively simple. The athlete does or does not provide a sample, which does or does not show evidence of illegal drugs. An innocent athlete then has minimal interference with training or lifestyle. By comparison investigating dishonesty in medical research is difficult, disruptive, and fraught with the danger of devastating liability for libel damages.

The key to detection of dishonesty in this case is someone like Wilmshurst who has the courage to blow the whistle and persist until the matter has been properly investigated. That is why I am so pleased that HealthWatch has honoured him, in contrast to the vilification he has received from other quarters.

John S Garrow chairman, Health Watch Rickmansworth, Hertfordshire WD3 7DQ johngarrow@aol.com

Competing interests: Formerly all of the following: colleague of Wilmshurst, editor in chief of the European Journal of Clinical Nutrition, member of $B M J$ hanging committee, and the Council for Publication Ethics (COPE); currently chairman of HealthWatch.

1 Ferriman A. Have editors got their priorities right? $B M J$ 2003;327:1113. (8 November.)

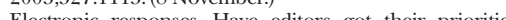
tectonic responses. Have editors got their prioritie ght? 2004).

Wilmshurst P. Institutional corruption in medicine. $B M$ $2002 \cdot 325 \cdot 1232-5$

\section{External checks must be imposed to} protect the public

EDITOR-With reference to Ferriman's article on editors' priorities, ${ }^{1}$ an inspectorate with authority to undertake random checks on research is needed because there is no adequate means to detect and deter research fraud. Academic institutions and hospitals have repeatedly failed to deal with misconduct. ${ }^{2}$ Some have even turned a blind eye to murder of patients by doctors. ${ }^{4}$ Institutions can no longer be trusted to deal internally with research misconduct.

Local research ethics committees lack the resources and inclination to deal with research fraud. Internet publication of raw data may help, but there are documented cases of falsified raw data. ${ }^{5}$ Furthermore, if you realise from inspecting the data on the internet that the paper was dishonest, what is your remedy? In my experience, the institution will refuse to act against the researchers, and editors will avoid retraction.

Inspection by an external agency could affect the running of research, but we accept checks in other activities, particularly when slackness and misconduct might affect public safety. We gain comfort from independent inspection of public transport and restaurants, although it creates difficulties for operators. Random alcohol breath testing of drivers increases safety for road users. I am pleased that my hand luggage is $\mathrm{x}$ rayed at airports.

In many activities checks are undertaken to ensure public safety. The public cannot have confidence that doctors and researchers are all honest and that employers will weed out the corrupt. External checks must be imposed.

Peter Wilmshurst consultant cardiologist Royal Shrewsbury Hospital, Shrewsbury, Shropshire SY3 8XQ peter.wilmshurst@rsh.nhs.uk

Competing interests: PW was the subject of the article because he received the HealthWatch award.

1 Ferriman A. Have editors got their priorities right? $B M J$ 003;327:1113. (8 November.)

2 Wilmshurst P. Institutional corruption in medicine. $B M J$ 2002;325:1232-5.

Wilmshurst P. The code of silence. Lancet 1997;349:567-9. 4 Stewart JB. Blind eye. How the medical establishment let a doctor get away with murder. New York: Simon and Schuster, 1999. 5 Broad W, Wade N. Betrayers of the truth. Fraud and deceit in science. Oxford: Oxford University Press, 1985.

\section{Everyone in science must be active in its} process

EDITOR-Ferriman discusses whether editors have their priorities right, raising important issues, particularly for associate editors of specialist journals. ${ }^{1}$ For example, I cannot review papers for the issues raised by Ferriman because there is simply no time Much of my time in the editorial process is spent on other duties.

Readers are important in the scientific process. They also have duties. The best science happens when all of us participate.

To obtain reviewers has become very difficult. Recently, I submitted a paper to a journal and after a considerable time I received the reviewers' comments from the editor. I was informed that the delay was due to having to send the paper to six different reviewers to obtain two reviews. Unfortunately, I experience the same problem.

Those in science need to be involved in science. When you are sent a paper for review, please review it; if you cannot notify the editor immediately. This will relieve some of the burden off the editor and associate editors and allow better consideration and evaluation of the issues raised by Ferriman.

John H Lange consultant

Envirosafe Training and Consultants, PO Box 114022, Pittsburgh, PA 15239, USA johnhlange@worldnet.att.net

Competing interests: JHL is associate editor of a journal that generally is not in competition with the $B M J$.

1 Ferriman A. Have editors got their priorities right? $B M$ J 2003;327:1113. (8 November.)

\section{bmj.com}

Letters appearing here are an edited selection of rapid responses originally posted on bmi.com

We ask for all letters to the editor to be submitted as rapid responses via bmj.com

For advice see: bmj.com/rapidresponses 